Pacific Journal of Mathematics

ON A PROBLEM OF COMPLETION IN BORNOLOGY 


\title{
ON A PROBLEM OF COMPLETION IN BORNOLOGY
}

\author{
V. B. Moscatelli
}

In this note an example is given to show that the bornological completion of a polar space need not be polar. Also, a theorem of Grothendieck's type is proved, from which necessary and sufficient conditions for the completion of a polar space to be again polar are derived.

1. Notation and terminology are as in [4]. In particular, b.c.s. means a locally convex, bornological linear space over the scalar field of real or complex numbers.

In $[4,5$. p. 160] Hogbe-Nlend lists, among unsolved problems in bornology, the following one, which was first raised by Buchwalter in his thesis [1, Remarque, p. 26]:

Is the bornological completion of a polar b.c.s. again polar?

The purpose of this note is to exhibit an example that answers this question in the negative. We also prove a theorem of Grothendieck's type for regular b.c.s. with weakly concordant norms, which enables us to give necessary and sufficient conditions for the completion of a polar b.c.s. to be polar.

2. For each $n$ let the double sequence $a^{n}=\left(\alpha_{i j}^{n}\right)$ be defined by $a_{i j}^{n}=j$ for $i \leqq n$ and all $j, a_{i j}^{n}=1$ for $i>n$ and all $j$, and denote by $E_{n}$ the normed space of scalar-valued double sequences $\left(x_{i j}\right)$ with only finitely many nonzero terms, under the norm

$$
\left\|\left(x_{i j}\right)\right\|_{n}=\sup _{i, j} \frac{\left|x_{i j}\right|}{a_{i j}^{n}} .
$$

Let $E$ be the bornological inductive limit of the spaces $E_{n}$; thus $E=E_{n}$ algebraically, and a set $B \subset E$ is bounded for the inductive limit bornology if and only if there exist positive integers $n, k$ such that $\left\|\left(x_{i j}\right)\right\|_{n} \leqq k$ for all $\left(x_{i j}\right) \in B$. It is easily seen that $E$ is a polar b.c.s. whose dual $E^{\times}$consists of all scalar-valued double sequences $\left(u_{i j}\right)$ such that

$$
\sum_{i, j=1}^{\infty} a_{i j}^{n}\left|u_{i j}\right|<\infty \quad \text { for all } n .
$$

By [1, Théorème (2.8.15)] the completion $\hat{E}$ of $E$ is given by $\hat{E}=\lim \hat{E}_{n}$ (bornological inductive limit), where $\hat{E}_{n}$ is the completion of the normed space $E_{n}$, i.e., the Banach space of scalar-valued double sequences $\left(x_{i j}\right)$ such that $\lim _{i, j \rightarrow \infty} x_{i j} / a_{i j}^{n}=0$ under the norm (1). It also 
follows from [1, Théorème (2.8.15)] that $\hat{E}^{\times}=E^{\times}$. Thus, it remains to show that the b.c.s. $\hat{E}$ is not polar with respect to the duality $\left\langle\hat{E}, E^{\times}\right\rangle$, i.e., that there is a bounded subset $B$ of $\hat{E}$ whose bipolar $B^{00}$ is unbounded. In fact, the set

$$
B=\left\{\left(x_{i j}\right) \in \hat{E}: \sup _{i, j}\left|x_{i j}\right| \leqq 1, \quad \lim _{i, j \rightarrow \infty} x_{i j}=0\right\}
$$

is bounded in the Banach space $\hat{E}_{1}$ and hence bounded in $\hat{E}$; however, since

$$
B^{00}=\left\{\left(x_{i j}\right) \in \hat{E}: \sup _{i, j}\left|x_{i j}\right| \leqq 1\right\},
$$

the sequence $\left\{\left(x_{i j}^{n}\right)\right\}$ with $x_{i j}^{n}=0$ for $i \neq n$ and all $j, x_{i j}^{n}=1$ for $i=n$ and all $j$, is contained in $B^{00}$ and yet is unbounded, for

$$
\left(x_{i j}^{n}\right) \in \hat{E}_{n} \sim \hat{E}_{n-1} .
$$

Therefore, $B^{00}$ is unbounded in $\hat{E}$.

3. Let $E$ be a regular b.c.s. with dual $E^{\times}$. For a bounded, absolutely convex set $B \subset E$ we set:

$E_{B}=$ the normed space spanned by $B$,

$\hat{B}=$ the completion of $B$ in the Banach space $\hat{E}_{B}$,

$E_{B}^{\prime}=$ the dual of $E_{B}$,

$B^{\prime}=$ the unit ball of $E_{B}^{\prime}$,

$B^{0}=$ the polar of $B$ in $E^{\times}$,

$B^{00}=$ the bipolar of $B$ in $\hat{E}$,

$p_{B}=$ the gauge of $B^{0}$ in $E^{\times}$,

$E_{B}^{\times}=$the normed space $E^{\times} / p_{B}^{-1}(0)$.

Moreover, we denote by $E^{\times *}$ the algebraic dual of $E^{\times}$and identify, as usual, $E_{B}^{\times}$with a $\sigma\left(E_{B}^{\prime}, E_{B}\right)$-dense subspace of $E_{B}^{\prime}$.

THEOREM 1. Let $E$ be a regular b.c.s. with weakly concordant norms. The completion $\hat{E}$ of $E$ consists, up to isomorphism, of all those linear functionals on $E^{\times}$whose restrictions to $B^{0}$ are bounded and $\sigma\left(E^{\times}, E_{B}\right)$-continuous for some bounded, absolutely convex set $B \subset E$. Moreover, for every base $\mathscr{B}$ of the bornology of $E$, the family $\widehat{\mathscr{B}}=\{\hat{B}: B \in \mathscr{B}\}$ is a base of the bornology of $\hat{E}$ and we have

$$
\hat{B}=\left\{x \in B^{\circ 0}: x \text { is } \sigma\left(E^{\times}, E_{E}\right) \text {-continuous on } B^{\circ}\right\}
$$

for every $\hat{B} \in \hat{\mathscr{B}}$.

Proof. If $x \in \hat{E}$, then by [3, Théorème 2, p. 221] there exists a bounded, absolutely convex subset $B$ of $E$ such that $x \in \hat{E}_{B}$; hence there is a sequence $\left\{x_{n}\right\} \subset E_{B}$ which converges to $x$ in the Banach 
space $\hat{E}_{B}$. It is easily seen that $\left\{x_{n}\right\}$ converges to an element $y \in E^{\times *}$ for the topology $\sigma\left(E^{\times *}, E^{\times}\right)$and, therefore, $y=x$. Since $\left\{x_{n}\right\}$ is a bounded sequence in $E_{B}$, there is a positive number $M$ such that $\left|\left\langle x_{n}, u\right\rangle\right| \leqq M$ for all $n$ and all $u \in B^{0}$. It follows that $\mid\langle x, u\rangle \leqq M$ for all $u \in B^{0}$. It remains to show that the restriction of $x$ to $B^{0}$ is $\sigma\left(E^{\times}, E_{B}\right)$-continuous. By Grothendieck's theorem $x$ is $\sigma\left(E_{B}^{\prime}, E_{B}\right)$ continuous on $B^{\prime}$; hence $x$ determines a unique bounded linear functional $z$ on $E_{B}^{\times}$whose restriction to the unit ball of $E_{B}^{\times}$is $\sigma\left(E_{B}^{\times}, E_{B}\right)$ continuous. Let $\phi$ be the canonical map $E^{\times} \rightarrow E_{B}^{\times}$. Since $p_{B}^{-1}(0)=$ $\left(E_{B}\right)^{0}, \phi$ is continuous from $\left(E^{\times}, \sigma\left(E^{\times}, E_{B}\right)\right)$ to $\left(E_{B}^{\times}, \sigma\left(E_{B}^{\times}, E_{B}\right)\right)$ and, therefore, the restriction of $x=z \circ \phi$ to $B^{0}$ is $\sigma\left(E^{\times}, E_{B}\right)$-continuous.

We have also proved that

$$
\hat{B} \subset\left\{x \in B^{00}: x \text { is } \sigma\left(E^{\times}, E_{B}\right) \text {-continuous on } B^{0}\right\} .
$$

Conversely, let $x \in E^{\times *}$ and suppose that, for some bounded, absolutely convex subset $B$ of $E$, the restriction of $x$ to $B^{0}$ is $\sigma\left(E^{\times}, E_{B}\right)$ continuous and satisfies

$$
|\langle x, u\rangle| \leqq M
$$

for all $u \in B^{0}$,

with $M>0$. By going through the mapping $\phi$ introduced above we see that $x$ determines a unique bounded linear functional $z$ on $E_{B}^{\times}(z \circ \phi=x)$ whose restriction to the unit ball $B^{0} / p_{B}^{-1}(0)$ of $E_{B}^{\times}$is $\sigma\left(E_{B}^{\times}, E_{B}\right)$-continuous. Now $\sigma\left(E_{B}^{\times}, E_{B}\right)$ is the topology induced by $\sigma\left(E_{B}^{\prime}, E_{B}\right)$ on $E_{B}^{\times}, B^{0} / p_{B}^{-1}(0)$ is a $\sigma\left(E_{B}^{\prime}, E_{B}\right)$-dense subset of $B^{\prime}$ and $B^{\prime}$ is a complete uniform space for the uniformity induced by that of $\left(E_{B}^{\prime}, \sigma\left(E_{B}^{\prime}, E_{B}\right)\right)$. It follows that $z$, being uniformly $\sigma\left(E_{B}^{\prime}, E_{B}\right)$-continuous on $B^{0} / p_{B}^{-1}(0)$, has a unique extension $y \in\left(E_{B}^{\prime}\right)^{*}$ which is uniformly $\sigma\left(E_{B}^{\prime}, E_{B}\right)$-continuous on $B^{\prime}$. By Grothendieck's theorem $y \in \hat{E}_{B}$ and, by (4),

$$
|\langle y, u\rangle| \leqq M
$$

for all $u \in B^{\prime}$.

This essentially proves the converse implication of (3). Thus (2) holds and the proof is complete, in virtue of the fact that if $\mathscr{B}$ is a base of the bornology of $E$, then $\widehat{\mathscr{B}}=\{\hat{B}: B \in \mathscr{B}\}$ is a base of the bornology of $\hat{E}$ by [3, Théorème 2, p. 221].

CoROLlaRY. Let $E$ be a regular b.c.s. with weakly concordant norms. Then $E$ is complete if and only if every linear functional on $E^{\times}$which is bounded and $\sigma\left(E^{\times}, E_{B}\right)$-continuous on $B^{\circ}$ for some bounded, absolutely convex subset $B$ of $E$, is $\sigma\left(E^{\times}, E\right)$-continuous on $E^{\times}$.

The referee has informed us of a Note [2] where Theorem 1 and 
its Corollary for polar b.c.s. are arrived at independently, and where counter examples to the same effect as that given in Section 2 are to be found. As every polar b.c.s. has weakly concordant norms (the converse being clearly false), the results in [2] are a particular case of the ones given here.

An immediate consequence of Theorem 1 is the following criterion for the completion of a polar b.c.s. to be again polar.

Theorem 2. Let $E$ be a polar b.c.s. The completion $\hat{E}$ of $E$ is polar if and only if every bounded subset $B$ of $E$ is contained in a bounded, absolutely convex set $C \subset E$ such that the restriction of every $x \in B^{00}$ to $C^{0}$ is $\sigma\left(E^{\times}, E_{C}\right)$-continuous.

\section{REFERENCES}

1. H. Buchwalter, Topologies, Bornologies et Compactologies, (Thesis, Lyon, 1968).

2. J-F. Colombeau, M. Grange and B. Perrot, Sur la complétion des espaces vectoriels bornologiques polaires, C.R.A.S., 273 (1972), 1481-1483.

3. H. Hogbe-Nlend, Complétion, tenseurs et nucléarité en bornologie, J. Math. Pure et Appl., 49 (1970), 193-288.

4. —_ Théorie des Bornologies et Applications, Springer-Verlag, Berlin-Heidelberg-New York, 1971.

Received April 25, 1972. This work was supported by an Italian National Research Council grant.

Westfield College, University of London 


\section{PACIFIC JOURNAL OF MATHEMATICS}

\section{EDITORS}

D. Gilbarg and J. Milgram

Stanford University

Stanford, California 94305

\author{
R. A. Beaumont \\ University of Washington \\ Seattle, Washington 98105
}

J. DuGUNDJI

Department of Mathematics

University of Southern California

Los Angeles, California 90007

Richard ARENS

University of California

Los Angeles, California 90024

\section{ASSOCIATE EDITORS}
E. F. BECKENBACH
B. H. NeumanN
F. WOLF
K. YosHIDA

\section{SUPPORTING INSTITUTIONS}

UNIVERSITY OF BRITISH COLUMBIA

CALIFORNIA INSTITUTE OF TECHNOLOGY

UNIVERSITY OF CALIFORNIA

MONTANA STATE UNIVERSITY

UNIVERSITY OF NEVADA

NEW MEXICO STATE UNIVERSITY

OREGON STATE UNIVERSITY

UNIVERSITY OF OREGON

OSAKA UNIVERSITY

\author{
UNIVERSITY OF SOUTHERN CALIFORNIA \\ STANFORD UNIVERSITY \\ UNIVERSITY OF TOKYO \\ UNIVERSITY OF UTAH \\ WASHINGTON STATE UNIVERSITY \\ UNIVERSITY OF WASHINGTON
* * * *
AMERICAN MATHEMATICAL SOCIETY \\ NAVAL WEAPONS CENTER
}

The Supporting Institutions listed above contribute to the cost of publication of this Journal, but they are not owners or publishers and have no responsibility for its content or policies.

Mathematical papers intended for publication in the Pacific Journal of Mathematics should be in typed form or offset-reproduced, (not dittoed), double spaced with large margins. Underline Greek letters in red, German in green, and script in blue. The first paragraph or two must be capable of being used separately as a synopsis of the entire paper. The editorial "we" must not be used in the synopsis, and items of the bibliography should not be cited there unless absolutely necessary, in which case they must be identified by author and Journal, rather than by item number. Manuscripts, in duplicate if possible, may be sent to any one of the four editors. Please classify according to the scheme of Math. Rev. Index to Vol. 39. All other communications to the editors should be addressed to the managing editor, Richard Arens, University of California, Los Angeles, California, 90024.

50 reprints are provided free for each article; additional copies may be obtained at cost in multiples of 50 .

The Pacific Journal of Mathematics is issued monthly as of January 1966. Regular subscription rate: $\$ 48.00$ a year (6 Vols., 12 issues). Special rate: $\$ 24.00$ a year to individual members of supporting institutions.

Subscriptions, orders for back numbers, and changes of address should be sent to Pacific Journal of Mathematics, 103 Highland Boulevard, Berkeley, California, 94708.

PUBLISHED BY PACIFIC JOURNAL OF MATHEMATICS, A NON-PROFIT CORPORATION

Printed at Kokusai Bunken Insatsusha (International Academic Printing Co., Ltd.), 270, 3-chome Totsuka-cho, Shinjuku-ku, Tokyo 160, Japan. 


\section{Pacific Journal of Mathematics}

\section{Vol. 46, No. 2 December, 1973}

Christopher Allday, Rational Whitehead products and a spectral sequence of

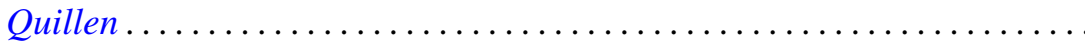

James Edward Arnold, Jr., Attaching Hurewicz fibrations with fiber

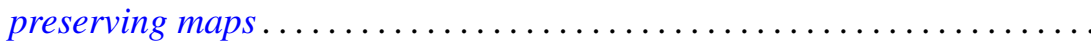

Catherine Bandle and Moshe Marcus, Radial averaging transformations with various metrics.................................

David Wilmot Barnette, A proof of the lower bound conjecture for convex

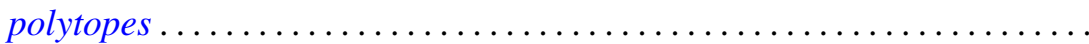

Louis Harvey Blake, Simple extensions of measures and the preservation of

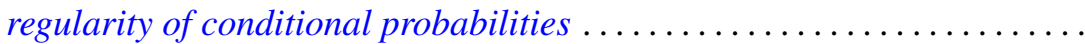

James W. Cannon, New proofs of Bing's approximation theorems for

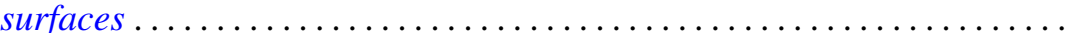

C. D. Feustel and Robert John Gregorac, On realizing HNN groups in

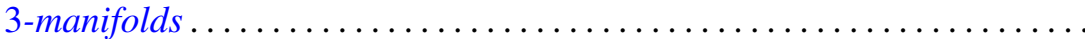

Theodore William Gamelin, Iversen's theorem and fiber algebras . . . . . . . . 389

Daniel H. Gottlieb, The total space of universal fibrations . . . . . . . . . . . .

Yoshimitsu Hasegawa, Integrability theorems for power series expansions of

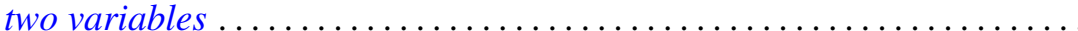

Dean Robert Hickerson, Length of period simple continued fraction expansion of $\sqrt{ } d$

Herbert Meyer Kamowitz, The spectra of endomorphisms of the disc algebra.

Dong S. Kim, Boundedly holomorphic convex domains

Daniel Ralph Lewis, Integral operators on $\mathscr{L}_{p}$-spaces ...

John Eldon Mack, Fields of topological spaces . . . . . . . . .

V. B. Moscatelli, On a problem of completion in bornology

Ellen Elizabeth Reed, Proximity convergence structures. .

Ronald C. Rosier, Dual spaces of certain vector sequence spaces .

Robert A. Rubin, Absolutely torsion-free rings

Leo Sario and Cecilia Wang, Radial quasiharmonic functions . .

James Henry Schmerl, Peano models with many generic classes .

H. J. Schmidt, The $\mathscr{F}$-depth of an $\mathscr{F}$-projector ............

Edward Silverman, Strong quasi-convexity. . . . . . . . . . . . . . . . . 549

Barry Simon, Uniform crossnorms ....................... 555

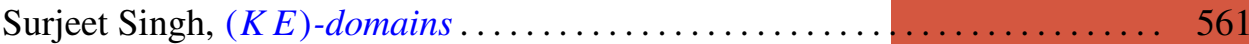

Ted Joe Suffridge, Starlike and convex maps in Banach spaces . . . . . . . . 575

Milton Don Ulmer, $C$-embedded $\Sigma$-spaces . . . . . . . . . . . . . . . . 591

Wolmer Vasconcelos, Conductor, projectivity and injectivity . . . . . . . . . 603 